\title{
Spectrophotometric Determination of Micro Amounts of Sulfide, Sulfite and Thiosulfate
}

\author{
Tomozo KoH and Yasuyuki MiURA \\ Department of Chemistry, Faculty of Science, Tokai University, Hiratsuka, Kanagawa 259-12
}

\begin{abstract}
The present method is based on the spectrophotometric measurement of an excess amount of iodine for the reaction of iodine with sulfide, sulfite and thiosulfate in a mixture after proper chemical treatments; it consists of three Procedures: I, II and III. The absorbance obtained by Procedure I corresponds to the sum of the thiosulfate and twice the sulfide and sulfite in the mixture. The absorbance obtained by Procedure II, where sulfite was masked by formaldehyde, corresponds to the sum of the thiosulfate and twice the sulfide. The absorbance obtained by Procedure III corresponds to only the amount of thiosulfate, because sulfite was masked by formaldehyde and sulfide was eliminated with the suspension of zinc carbonate hydroxide. The conditions under which all the three sulfur species in a mixture can be stable and react stoichiometrically with iodine were established. The method is applicable to the determination of sulfur species in amounts more than $0.05 \mu \mathrm{mol}$ and gave a relative standard deviation of $3 \%$ at $0.4 \mu \mathrm{mol}$ level. It has been applied to the determination of sulfide, sulfite and thiosulfate in various amounts in several fumarolic condensate samples.
\end{abstract}

Keywords Sulfur anions determination, sulfide-sulfite-thiosulfate mixture, iodine, spectrophotometry, fumarolic condensates

Sulfur forms various species, which can be classified into two types; the first group consumes iodine in an acid medium and the other does not. The former group includes sulfides, sulfites and thiosulfates. The identification and determination of these sulfur species are difficult, particularly when mixed with one another in a solution, because they are labile and participate in complex equilibria with the other sulfur compounds formed by their auto-redox reactions. Various investigations have been made regarding the determination of either one or two sulfur species in mixture of two species such as sulfide (polysulfide included) and thiosulfate ${ }^{1-5}$, sulfide and sulfite ${ }^{6,7}$, and sulfite and thiosulfate. ${ }^{8-12}$ Recently, ion chromatography has been applied to the separation of sulfite, thiosulfate and sulfate $^{13}$, and also to the analysis of mixtures of sulfite, thiosulfate, sulfate and thiocyanate. ${ }^{14}$ However, no consideration has been given to the determination of sulfide, sulfite and thiosulfate in a mixture.

In the past, classical iodimetric titration methods ${ }^{15,16}$ have been extensively employed for the determination of sulfide, sulfite and thiosulfate in a mixture. Kilroy ${ }^{17}$ has proposed a titrimetric method for the mixture of sulfide, sulfite, thiosulfate and dithionite. However, these methods are not suitable for micro amounts of sulfur species. In addition, the procedure ${ }^{17}$ for the determination of thiosulfate is too complicated and time-consuming. Ono ${ }^{18}$ has devised a method for the determination of sulfide, sulfite and thiosulfate in the leaching solution of blast-furnace slags by ion exchange chromatography. In the present study, the conditions of stabilization of sulfide and sulfite mixed with each other were investigated to avoid time-dependent change in chemical composition of the sample solution containing soluble sulfide, sulfite and thiosulfate. The present paper is based on the spectrophotometric measurement of an excess amount of iodine for the reaction of iodine with sulfide, sulfite and thiosulfate after proper chemical treatments.

\section{Experimental}

\section{Reagents and apparatus}

All chemicals used were of analytical grade and were used without further purification. The water was redistilled. A sulfide solution $(0.05 \mathrm{M})$ was prepared by dissolving $2.4 \mathrm{~g}$ of sodium sulfide nonahydrate whose surface was washed with oxygen-free water (the water on the solid sulfide was removed by absorption with filter paper) in $200 \mathrm{ml}$ of water. The solution was continuously deaerated with nitrogen gas, and then standardized by iodimetry. ${ }^{19}$ Working standard sulfide solutions were prepared by appropriate dilution with oxygen-free water. These standards must be used within $30 \mathrm{~min}$ after standardization, because the concentration of sulfide decreases due to its oxidation on further standing. A standard sulfite solution was prepared by dissolving sodium hydrogensulfite in oxygen-free water, and was standardized by iodimetry. ${ }^{20}$ Working standards were obtained by suitable dilution. A standard thiosulfate solution was prepared 
by dissolving a given amount of sodium thiosulfate pentahydrate in oxygen-free water containing a small amount of sodium carbonate as a stabilizer, and standardized by iodimetry ${ }^{20}$ a week after preparation. Working standard thiosulfate solutions were prepared by appropriate dilution as required.

A standard iodate-iodide solution was prepared by adding $50.0 \mathrm{ml}$ of $1.00 \times 10^{-2} \mathrm{~N}\left(=1.67 \times 10^{-3} \mathrm{M}\right)$ standard iodate to a solution containing $0.2 \mathrm{~g}$ of sodium carbonate and $72.6 \mathrm{~g}$ of potassium iodide, and diluting it to $500 \mathrm{ml}$ to give a $1.00 \times 10^{-3} \mathrm{~N}$ iodate in $0.87 \mathrm{M}$ iodide solution. An iodide solution of $0.87 \mathrm{M}$ was prepared by dissolving $72.6 \mathrm{~g}$ of potassium iodide in water containing $0.2 \mathrm{~g}$ of sodium carbonate and diluting it to $500 \mathrm{ml}$. This solution was used for the correction of air-oxidation of iodide. Suspension of zinc carbonate hydroxide was prepared by mixing $5 \%(\mathrm{w} / \mathrm{v})$ zinc acetate and $7.5 \%(\mathrm{w} / \mathrm{v})$ sodium carbonate in equal volume ratio immediately before use.

Buffer solutions required for adjusting the $\mathrm{pH}$ of reaction solutions were prepared by the mixing of formic acid $(0.2 \mathrm{M})$ and sodium hydroxide $(0.2 \mathrm{M})$, acetic acid $(0.2 \mathrm{M})$ and sodium acetate $(0.2 \mathrm{M})$, sodium hydrogenmaleate $(0.2 \mathrm{M})$ and sodium maleate $(0.2 \mathrm{M})$, boric acid $(0.2 \mathrm{M})$ containing potassium chloride $(0.2$ $\mathrm{M})$ and sodium hydroxide $(0.2 \mathrm{M})$, sodium hydrogencarbonate $(0.2 \mathrm{M})$ and sodium carbonate $(0.2 \mathrm{M})$, and ammonium chloride $(0.2 \mathrm{M})$ and ammonia $(0.2 \mathrm{M})$, in various volume ratios. In addition, sodium carbonate and sodium hydroxide solutions were used for the adjustment of pH. The buffer solutions of $\mathbf{p H ~} 5.0$ used in Procedure I and pH 6.2 in both Procedures II and III were obtained by mixing $100 \mathrm{ml}$ of $0.2 \mathrm{M}$ acetic acid with $200 \mathrm{ml}$ of $0.2 \mathrm{M}$ sodium acetate, and $100 \mathrm{ml}$ of $0.2 \mathrm{M}$ sodium hydrogenmaleate with $200 \mathrm{ml}$ of 0.2 $\mathrm{M}$ sodium maleate, respectively.

All spectrophotometric measurements were made with a Shimadzu Model UV-100-02 spectrophotometer with $10-$ mm quartz cells. $\mathrm{pH}$ was measured with a Hitachi-Horiba Model $\mathrm{M}-7$ pH meter.

\section{Procedure}

Prepare the following three reaction mixtures for the determination of sulfide, sulfite and thiosulfate in mixtures.

Procedure I. Determination of sulfide, sulfite and thiosulfate in the mixture. Place $1 \mathrm{ml}$ of $0.2 \mathrm{M}$ acetate buffer ( $\mathrm{pH} 5.0), 1 \mathrm{ml}$ of $0.1 \%(\mathrm{w} / \mathrm{v})$ zinc acetate, and then a $10.0-\mathrm{ml}$ aliquot of the sample solution containing sulfide, sulfite and thiosulfate to a $25-\mathrm{ml}$ volumetric flask. The $\mathrm{pH}$ of the solution is thereby brought to 5.1 .

Procedure II. Determination of sulfide and thiosulfate in the mixture. Place $1 \mathrm{ml}$ of $0.2 \mathrm{M}$ maleate buffer $(\mathrm{pH}$ $6.2), 1 \mathrm{ml}$ of $0.1 \%(\mathrm{w} / \mathrm{v})$ zinc acetate, and a $10.0-\mathrm{ml}$ aliquot of the sample solution to a $25-\mathrm{ml}$ volumetric flask. Then add $1 \mathrm{ml}$ of $1.5 \times 10^{-2} \mathrm{M}$ formaldehyde, and allow the mixture to stand for at least $1 \mathrm{~min}$. The $\mathrm{pH}$ of the solution is thereby brought to 6.2 .
Procedure III. Determination of thiosulfate in the mixture. Place $1 \mathrm{ml}$ of $0.2 \mathrm{M}$ maleate buffer ( $\mathrm{pH}$ $6.2), 1 \mathrm{ml}$ of $1.5 \times 10^{-2} \mathrm{M}$ formaldehyde, and then a $10.0-\mathrm{ml}$ aliquot of the sample solution to a $50-\mathrm{ml}$ beaker. Allow the mixture to stand for $1 \mathrm{~min}$, then add two drops of suspension of freshly precipitated zinc carbonate hydroxide. In this case, the $\mathrm{pH}$ of the solution was adjusted to 6.8 , and the sulfide in the mixture was precipitated. Filter off the precipitate through Toyo No. 6 filter paper, wash it thoroughly with water, and transfer the filtrate and washings to a 25 -ml volumetric flask.

To these three mixtures of Procedures I, II and III, add $2 \mathrm{ml}$ of $2 \mathrm{M}$ acetic acid and $2.4 \mathrm{ml}$ of $1.00 \times 10^{-3} \mathrm{~N}$ standard iodate in $0.87 \mathrm{M}$ iodide solution, then fill the flask to the mark with water. Mix the contents of the flasks well, and measure the absorbance of the solution against water at $350 \mathrm{~nm}$ of maximum absorption for triiodide ion. In Procedures I and II, it is necessary to add standard iodate in iodide solution immediately after the addition of acetic acid, otherwise hydrogen sulfide is evolved.

\section{Results and Discussion}

\section{Calibration graphs}

A series of standard solutions $(10.0 \mathrm{ml})$ of thiosulfate, sulfide and sulfite were treated according to Procedure I. It is well known that thiosulfate, sulfide and sulfite react with iodine in an acid medium as follows ${ }^{21}$ :

$$
\begin{aligned}
& 2 \mathrm{~S}_{2} \mathrm{O}_{3}{ }^{2-}+\mathrm{I}_{2} \rightarrow \mathrm{S}_{4} \mathrm{O}_{6}{ }^{2-}+2 \mathrm{I}^{-} \\
& \mathrm{S}^{2-}+\mathrm{I}_{2} \quad \rightarrow \mathrm{S}+2 \mathrm{I}^{-}
\end{aligned}
$$

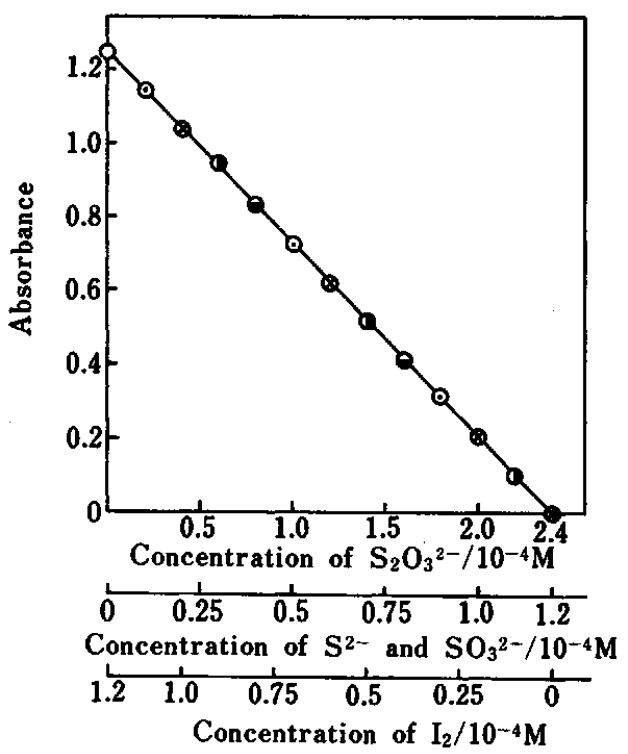

Fig. 1 Calibration graphs for thiosulfate, sulfide, sulfite and iodine obtained by Procedure $\mathrm{I} .(0) \mathrm{S}_{2} \mathrm{O}_{3}{ }^{2-},(\otimes) \mathrm{S}^{2-},(\odot)$ $\mathrm{SO}_{3}{ }^{2-},(\theta) \mathrm{I}_{2}$. 


$$
\mathrm{SO}_{3}{ }^{2-}+\mathrm{I}_{2}+\mathrm{H}_{2} \mathrm{O} \rightarrow \mathrm{SO}_{4}{ }^{2-}+2 \mathrm{I}^{-}+2 \mathrm{H}^{+} .
$$

As can be seen in Fig. 1, the calibration graphs for thiosulfate, sulfide and sulfite obtained by procedure I coincided with one another when the molar concentration scale for sulfide and sulfite was drawn to twice the scale for thiosulfate concentration. Moreover, these graphs accorded with that for iodine when the molar concentration scale for iodine was drawn oppositely to that for sulfur species. The calibration plots for both sulfide and thiosulfate in the presence of sulfite $\left(1.2 \times 10^{-4} \mathrm{M}\right)$ obtained by Procedure II and that for thiosulfate in the presence of both sulfide $\left(1.2 \times 10^{-4} \mathrm{M}\right)$ and sulfite $\left(1.2 \times 10^{-4} \mathrm{M}\right)$ by Procedure III were also in complete accordance with the calibration graph for iodine in Fig. 1. These experimental facts show that any species of sulfide, sulfite and thiosulfate can react stoichiometrically with iodine even in the presence of others without changes in the chemical composition under the conditions given in Procedures I, II and III.

\section{Stability of sulfide and sulfite in their mixture}

Sulfide is a very unstable species, particularly in an aqueous solution; low results were obtained in the determination of sulfide because of its evolution and/or oxidation. Therefore, an attempt was made to fix sulfide as zinc sulfide ${ }^{19}$ for its stabilization. The amounts of $1 \mathrm{ml}$ of $0.06-0.3 \%(\mathrm{w} / \mathrm{v})$ zinc acetate were sufficient to stabilize sulfide. When $1 \mathrm{ml}$ of $0.1 \%$ zinc acetate was added as in Procedure $I$, the sulfide was stable for $10 \mathrm{~min}$ at $\mathrm{pH} 4.5$, for $30 \mathrm{~min}$ at $\mathrm{pH} 5.1$ and for $15 \mathrm{~min}$ at $\mathrm{pH} \mathrm{7.8.} \mathrm{On} \mathrm{the} \mathrm{other} \mathrm{hand,} \mathrm{sulfite} \mathrm{was}$ stable for $15 \mathrm{~min}$ at $\mathrm{pH} 4.5$, for $20 \mathrm{~min}$ at $\mathrm{pH} 5.1$ and for $10 \mathrm{~min}$ at $\mathrm{pH} 6.2$. Figure 2 shows that sulfide and sulfite are stable for $5 \mathrm{~min}$ over the $\mathrm{pH}$ range 4.5-7.8 and over the $\mathrm{pH}$ range $3.8-6.4$, respectively. An increase in absorbance for sulfide below pH 4.5 and for sulfite below pH 3.8 is thought to be predominantly caused by the evolution of hydrogen sulfide and sulfur

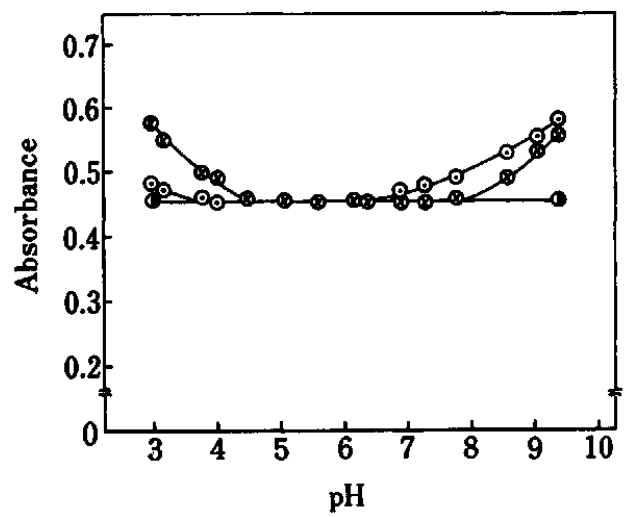

Fig. 2 Effect of pH on the stability of sulfide, sulfite and thiosulfate. Standing time: $5 \mathrm{~min}$. The conditions are as described in Procedure $\mathrm{I}$, except $\mathrm{pH}$ and standing time.

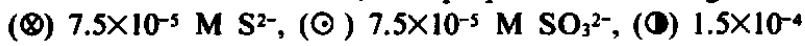
$\mathrm{M} \mathrm{S}_{2} \mathrm{O}_{3}{ }^{2-}$. dioxide. An increase in absorbance for sulfide above pH 7.8 and for sulfite above pH 6.4 is probably due to the oxidation of sulfide and sulfite. Sulfide proved not to react with sulfite when fixed as zinc sulfide, and even the mixtures with various molar ratios of sulfide to sulfite were stable for at least $15 \mathrm{~min}$ at $\mathrm{pH} 5.1$ and could be stable for $5 \mathrm{~min}$ over the $\mathrm{pH}$ range 4.5-6.4. It was therefore concluded that each sulfide, sulfite and thiosulfate in a mixture can react quantitatively with iodine under the conditions given in Procedure I without time-dependent changes in the chemical composition of sample.

\section{Masking of sulfite with formaldehyde}

In order to obtain the absorbance for total amounts of both sulfide and thiosulfate in the presence of sulfite according to Procedure II, the reaction of sulfite with iodine must be completely prevented. An attempt was made to mask the sulfite with formaldehyde. ${ }^{9}$ It was confirmed that sulfite was completely masked in the pH range $5.6-8.6$, when $1 \mathrm{ml}$ of $1.5 \times 10^{-2} \mathrm{M}$ formaldehyde was added and the mixture was allowed to stand for $1 \mathrm{~min}$. As mentioned above, the sulfide fixed as zinc sulfide was stable over the $\mathrm{pH}$ range 4.5 7.8. Consequently, iodine reacted with only both sulfide and thiosulfate even in the presence of sulfite when the sulfite was masked by formaldehyde over the $\mathrm{pH}$ range of 5.6-7.8.

\section{Removal of sulfide}

In Procedure III, the reaction of both sulfide and sulfite with iodine must be prevented in order to obtain the absorbance for thiosulfate. Sulfide was precipitated with 2 drops of suspension of zinc carbonate hydroxide and eliminated by filtering off the precipitate. Figure 3 shows how the sulfide could be removed by varying the $\mathrm{pH}$ of mixture solution. The absorbance for sulfide coincided with the reagent blank

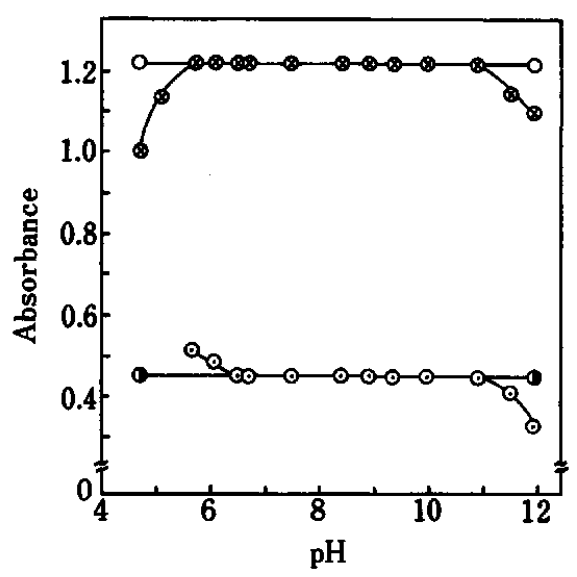

Fig. 3 Effect of $\mathrm{pH}$ on the removal of sulfide. The conditions are as described in Procedure III, except pH. (O) reagent blank, $(\otimes) 1.2 \times 10^{-4} \mathrm{M} \mathrm{S}^{2-}$, (O) $1.5 \times 10^{-4} \mathrm{M} \mathrm{S}_{2} \mathrm{O}_{3}{ }^{2-}$, (๑) $1.5 \times 10^{-4} \mathrm{M} \mathrm{S}_{2} \mathrm{O}_{3}{ }^{2-}$ in the presence of $\mathrm{S}^{2-}\left(1.2 \times 10^{-4} \mathrm{M}\right)$. 
over the pH range 5.7-10.9. On the other hand, the absorbance for thiosulfate in the presence of sulfide was in complete agreement with the absorbance for thiosulfate in the absence of sulfide over the $\mathrm{pH}$ range 6.5-10.9. Higher absorbances for thiosulfate below $\mathrm{pH} 6.5$ could be attributed to the incomplete transference of thiosulfate into the filtrate, probably owing to the occlusion of thiosulfate in the precipitate. The maximum determinable amount $(1.2 \mu \mathrm{mol})$ of sulfide was completely removed by adding 1 to 5 drops of the above-mentioned suspension. As stated above, the reactions of sulfite and sulfide with iodine could be prevented over the $\mathrm{pH}$ ranges of 5.6-8.6 and 6.5-10.9, respectively. Therefore, we could obtain the absorbance for thiosulfate in the presence of sulfite and sulfide by Procedure III, where the solution was buffered at the $\mathrm{pH}$ range $6.5-8.6$ after the addition of the suspension.

\section{Determination of sulfide, sulfite and thiosulfate in their mixture}

The three sulfur species in their mixture give the following equivalents in three Procedures:

$$
\begin{aligned}
& \text { Procedure I } \equiv 2 \mathrm{~S}^{2-}+2 \mathrm{SO}_{3}{ }^{2-}+\mathrm{S}_{2} \mathrm{O}_{3}{ }^{2-} \\
& \text { Procedure } \mathrm{II} \equiv 2 \mathrm{~S}^{2-}+\mathrm{S}_{2} \mathrm{O}_{3}{ }^{2-} \\
& \text { Proceudre } \mathrm{III} \equiv \mathrm{S}_{2} \mathrm{O}_{3}{ }^{2-} \text {. }
\end{aligned}
$$

The absorbance obtained by Procedure I corresponds to the sum of twice the sulfide (see Eq. 2) and sulfite (Eq. 3), and the thiosulfate (Eq. 1) in the mixture. The absorbance obtained by Procedure II, where sulfite was masked by formaldehyde, corresponds to the sum of the thiosulfate and twice the sulfide in the mixture. The absorbance obtained by Procedure III corresponds to only the amount of the thiosulfate in the mixture solution, because sulfite was masked by formaldehyde and sulfide was eliminated by the suspension of zinc carbonate hydroxide. Moreover, the calibration graphs for sulfide, sulfite and thiosulfate

Table 1 Determination of each sulfur species in 10- $\mathrm{ml} \mathrm{mix-}$ ture solution of sulfide, sulfite and thiosulfate

\begin{tabular}{ccccccc}
\hline \multicolumn{3}{c}{ Taken $/ \mu \mathrm{mol}$} & & \multicolumn{3}{c}{ Found $/ \mu \mathrm{mol}$} \\
\cline { 1 - 2 } \cline { 5 - 6 } $\mathrm{S}^{2-}$ & $\mathrm{SO}_{3}{ }^{2-}$ & $\mathrm{S}_{2} \mathrm{O}_{3}{ }^{2-}$ & & $\mathrm{S}^{2-}$ & $\mathrm{SO}_{3}{ }^{2-}$ & $\mathrm{S}_{2} \mathrm{O}_{3}{ }^{2-}$ \\
\hline 0.35 & 0.50 & & & 0.35 & 0.51 & \\
0.80 & 0.20 & & & 0.80 & 0.21 & \\
& 0.80 & 0.40 & & 0.81 & 0.39 \\
& 0.40 & 1.00 & & 0.40 & 1.00 \\
0.70 & & 0.50 & & 0.72 & & 0.50 \\
0.60 & & 0.90 & & 0.61 & & 0.90 \\
0.50 & 0.40 & 0.30 & & 0.52 & 0.40 & 0.28 \\
0.25 & 0.25 & 0.50 & & 0.25 & 0.24 & 0.51 \\
0.30 & 0.45 & 0.65 & & 0.30 & 0.46 & 0.64 \\
0.40 & 0.40 & 0.40 & & 0.40 & 0.41 & 0.30 \\
\hline
\end{tabular}

were in complete agreement with one another when plotted in terms of equivalent concentrations. The following equations can thus be obtained: $\left[\mathrm{S}^{2-}\right]=$ (II-III) $/ 2,\left[\mathrm{SO}_{3}{ }^{2-}\right]=(\mathrm{I}-\mathrm{II}) / 2$ and $\left[\mathrm{S}_{2} \mathrm{O}_{3}{ }^{2-}\right]=\mathrm{III}$, where I, II and III denote the molar concentration of thiosulfate which was determined from the calibration graph for thiosulfate in Fig. 1 using the absorbance obtained by Procedures I, II and III, respectively. Table 1 shows that the present method can be successfully applied to the determination of sulfide, sulfite and thiosulfate mixed in various ratios with an error below $\pm 0.02 \mu \mathrm{mol}$.

The precision was obtained from six results for three $10-\mathrm{ml}$ aliquots of sample solution containing $0.4 \mu \mathrm{mol}$ of each species of sulfide, sulfite and thiosulfate. The method gave a mean value of $0.4 \mu \mathrm{mol}$ with a standard deviation of $0.01 \mu \mathrm{mol}$ and a relative standard deviation of $2.5 \%$ for sulfide, $0.41 \mu \mathrm{mol}$ with 0.0063 and $1.5 \%$ for sulfite, and $0.39 \mu \mathrm{mol}$ with 0.013 and $3.2 \%$ for thiosulfate.

\section{Effect of diverse ions}

Three aliquots $(10 \mathrm{ml})$ of solution containing various amounts of foreign ions and $0.4 \mu \mathrm{mol}$ of sulfide, sulfite and thiosulfate respectively were treated according to Procedures I, II and III. The amounts of diverse ions that caused errors below $5 \%$ are listed in Table 2 except $\mathrm{Cu}$ (II) and $\mathrm{Fe}$ (III). The interference of $\mathrm{Mn}$ (II) was due to the incomplete masking of sulfite in its presence under the conditions given in Procedure II. All the other ions could be tolerated in amounts of about 1000 ppm.

Table 2 Effect of diverse ions on the determinations of 0.4

\begin{tabular}{|c|c|c|c|c|c|}
\hline \multirow{2}{*}{ Ion } & \multirow{2}{*}{ Added as ${ }^{a}$} & \multirow{2}{*}{ Conc, ppm } & \multicolumn{3}{|c|}{ 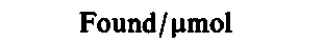 } \\
\hline & & & $\mathbf{S}^{2-}$ & $\mathrm{SO}_{3}{ }^{2-}$ & $\mathrm{S}_{2} \mathrm{O}_{3}{ }^{2-}$ \\
\hline $\mathrm{Na}^{+}$ & $\mathrm{Na}_{2} \mathrm{SO}_{4}$ & 1000 & 0.41 & 0.38 & 0.41 \\
\hline $\mathbf{K}^{+}$ & $\mathrm{K}_{2} \mathrm{SO}_{4}$ & 1000 & 0.42 & 0.38 & 0.40 \\
\hline $\mathrm{NH}_{4}{ }^{+}$ & $\mathrm{NH}_{4} \mathrm{NO}_{3}$ & 1000 & 0.41 & 0.39 & 0.41 \\
\hline $\mathbf{M g}^{2+}$ & $\mathrm{Mg}\left(\mathrm{NO}_{3}\right)_{2}$ & 1000 & 0.41 & 0.39 & 0.39 \\
\hline $\mathrm{Ca}^{2+}$ & $\mathrm{Ca}\left(\mathrm{NO}_{3}\right)_{2}$ & 1000 & 0.42 & 0.38 & 0.39 \\
\hline $\mathrm{Zn}^{2+}$ & $\mathrm{ZnSO}_{4}$ & 1000 & 0.41 & 0.39 & 0.40 \\
\hline $\mathrm{Cd}^{2+}$ & $\mathrm{CdSO}_{4}$ & 1000 & 0.41 & 0.39 & 0.39 \\
\hline $\mathrm{Mn}^{2+}$ & $\mathrm{MnSO}_{4}$ & 1 & 0.41 & 0.38 & 0.41 \\
\hline $\mathrm{Cu}^{2+}$ & $\mathrm{CuSO}_{4}$ & I & 0.30 & 0.39 & 0.42 \\
\hline $\mathrm{Pb}^{2+}$ & $\mathrm{Pb}\left(\mathrm{NO}_{3}\right)_{2}$ & 10 & 0.40 & 0.40 & 0.40 \\
\hline $\mathrm{Fe}^{3+}$ & $\mathrm{Fe}\left(\mathrm{NO}_{3}\right)_{3}$ & 10 & 0.42 & 0.32 & 0.41 \\
\hline $\mathrm{Al}^{3+}$ & $\mathrm{Al}\left(\mathrm{NO}_{3}\right)_{3}$ & 100 & 0.42 & 0.39 & 0.38 \\
\hline $\mathrm{F}^{-}$ & $\mathrm{NaF}$ & 1000 & 0.42 & 0.38 & 0.39 \\
\hline $\mathrm{Cl}^{-}$ & $\mathrm{NaCl}$ & 1000 & 0.40 & 0.38 & 0.42 \\
\hline $\mathrm{Br}$ & $\mathrm{KBr}$ & 1000 & 0.41 & 0.38 & 0.40 \\
\hline $\mathbf{I}^{-}$ & $\mathbf{K I}$ & 1000 & 0.42 & 0.38 & 0.39 \\
\hline $\mathrm{NO}_{3}^{-}$ & $\mathrm{NaNO}_{3}$ & 1000 & 0.41 & 0.38 & 0.40 \\
\hline $\mathrm{HCO}_{3}^{-}$ & $\mathrm{NaHCO}_{3}$ & 1000 & 0.42 & 0.38 & 0.40 \\
\hline $\mathrm{SO}_{4}{ }^{2-}$ & $\mathrm{Na}_{2} \mathrm{SO}_{4}$ & 1000 & 0.41 & 0.38 & 0.41 \\
\hline $\mathrm{H}_{2} \mathrm{PO}_{4}^{-}$ & $\mathrm{NaH}_{2} \mathrm{PO}_{4}$ & 1000 & 0.39 & 0.39 & 0.42 \\
\hline $\mathrm{HAsO}_{4}{ }^{2-}$ & $\mathrm{Na}_{2} \mathrm{HAsO}_{4}$ & 1000 & 0.42 & 0.38 & 0.40 \\
\hline
\end{tabular}
$\mu \mathrm{mol}$ of sulfide, sulfite and thiosulfate in $10-\mathrm{ml}$ mixture solution

a. Water of hydration was omitted for brevity. 
Table 3 Determination of sulfide, sulfite and thiosulfate in $10-\mathrm{ml}$ sample solution of fumarolic condensates

\begin{tabular}{cccc}
\hline Sample & $\begin{array}{c}\mathrm{S}^{2-} / \\
\mu \mathrm{mol}\end{array}$ & $\begin{array}{c}\mathrm{SO}_{3}{ }^{2-} / \\
\mu \mathrm{mol}\end{array}$ & $\begin{array}{c}\mathrm{S}_{2} \mathrm{O}^{2-} / \\
\mu \mathrm{mol}\end{array}$ \\
\hline $\mathrm{A}$ & 7.12 & 314 & 1.96 \\
$\mathrm{~B}$ & $\mathrm{ND}^{\mathrm{a}}$ & 0.06 & 0.36 \\
$\mathrm{C}$ & 0.07 & 0.12 & 0.52 \\
$\mathrm{D}$ & 7.58 & 44.1 & 0.64 \\
\hline
\end{tabular}

a. ND means "not detected".

\section{Determination of sulfide, sulfite and thiosulfate in fumarolic condensates}

The present method was applied to the determination of sulfide, sulfite and thiosulfate in several fumarolic condensates. The results are shown in Table 3. Acetate buffers and maleate buffers of various $\mathbf{p H}$ and ammonia were used to adjust $\mathrm{pH}$ of the sample solutions to the optimal pH ranges in Procedures I, II and III. The amounts of formaldehyde used to mask the sulfite in samples $A$ and D were much more than those in the recommended Procedures II and III. Table 3 shows that the present method is applicable to the determination of sulfide, sulfite and thiosulfate in various amounts in fumarolic condensates.

We wish to express our thanks to Dr. Minoru Yoshida of Tokyo Institute of Technology for supplying the fumarolic condensate samples.

\section{References}

1. L. Szekeres, Fresenius' Z. Anal. Chem., 178, 81 (1960).
2. M. Wronśki, Fresenius' Z. Anal. Chem., 179, 350 (1961).

3. L. Legradi, Analyst [London], 89, 854 (1961).

4. S. A. Kiss, Fresenius' Z. Anal. Chem., 188, 341 (1962).

5. H. Satake, T. Hisano and S. Ikeda, Bull. Chem. Soc. Jpn., 54, 1968 (1981).

6. D. D. Nygaard, Anal. Chim. Acta, 127, 257 (1981).

7. N. K. Murty and N. V. S. Rao, Analyst [London], 108, 119 (1983).

8. T. Koh and K. Taniguchi, Anal. Chem., 45, 2018 (1973).

9. T. Koh and K. Taniguchi, Anal. Chem., 46, 1679 (1974).

10. T. Koh, K. Taniguchi and I. Iwasaki, Bull. Chem. Soc. Jpn., 51, 164 (1978).

11. T. Koh, K. Taniguchi, Y. Miura and I. Iwasaki, Nippon Kagaku Kaishi, 1979, 348.

12. L. Brown and L. Szekeres, Talanta, 26, 414 (1979).

13. T. Sundén, M. Lindgren and A. Cedergren, Anal. Chem., 55, 2 (1983).

14. C. O. Moses, D. K. Nordstrom and A. L. Mills, Talanta, 31, 331 (1984).

15. A. Kurtenacker and R. Wollack, Z. Anorg. Allgem. Chem., 161, 201 (1927).

16. H. Wiele, Fresenius' Z. Anal. Chem., 273, 15 (1975).

17. W. P. Kilroy, Talanta, 30, 419 (1983).

18. A. Ono, Bunseki Kagaku, 35, 476 (1986).

19. B. J. Heinrich, M. D. Grimes and J. E. Puckett, in "Treatise on Analytical Chemistry", Part II, Volume 7, p. 75, ed. I. M. Kolthoff and P. J. Elving, Interscience, New York (1960).

20. L. V. Haff, in "The Analytical Chemistry of Sulfur and Its Compounds", Part I, pp. 225-236, ed. J. H. Karchmer, Wiley-Interscience, New York (1970).

21. I. M. Kolthoff, I. B. Sandell, E. J. Meehan and S. Bruckenstein, "Quantitative Chemical Analysis", 4th ed., p. 842, Macmillan, London (1969). 